\title{
Sobre as políticas públicas de educação na cidade do Rio de Janeiro entre 1922-1935
}

André Luiz Paulilo

Palavras-chave: história da

educação brasileira; reforma de

ensino (história), ensino público;

políticas públicas; cultura

brasileira.

\section{Resumo}

Interroga sobre o alcance das reformas da instrução pública na transformação da cultura escolar brasileira entre 1922 e 1935. Destaca a importância das políticas públicas da educação na cidade do Rio de Janeiro para organizar um sistema escolar nacional. Discorre sobre relatos acerca das experiências de reforma demonstrando a valorização do estatuto estratégico e da prática pedagógica na montagem das políticas públicas. Conclui indicando o modo por meio do qual a reconstrução institucional do aparelho escolar desenvolveu-se como uma política de governo.

A elaboração de um espaço escolar distinto de outros espaços sociais, a conformação de um corpo profissional, o surgimento e proliferação das escolas normais e a consolidação de saberes pedagógicos e escolares conduziram as análises históricas a uma série de interrogações difíceis acerca das práticas escolares: Como elas se materializavam? Quais os seus efeitos? Como traduziram o movimento de atualização da sociedade que ajudaram a construir? Que sistema de relações pode ser descrito por meio delas? (Nunes, 1992). Buscando esclarecer essas questões, pesquisadores e pesquisadoras da educação brasileira distinguiram diversos critérios de construção dos objetos de análise. Marta Carvalho (1989) delimitou os limiares historiográficos da narrativa produzida pela memória escolanovista. Maria Lúcia Spedo Hilsdorf (1999a) descreveu as possibilidades de trabalho inédito e abrangente da pesquisa em fontes oitocentistas. Luciano Mendes de Faria Filho (1999) e Cynthia Greive Veiga (2000) analisaram as conseqüências culturais da escolarização, em que aspectos da vida provincial podem ser detectados e como podem ser apreendidas pela análise histórica. Quanto à materialidade das práticas, é a alteração dos significados enunciados da forma e da cultura em voga nas escolas que Diana Gonçalves Vidal (2000) interroga na transição do Império para a República.

De fato, procura-se atualmente detectar o domínio de uma mudança efetiva. A instrução pública oitocentista - e, de uma maneira geral, o seu processo de escolarização - passou a encadear os tempos, os espaços, os sujeitos, os conhecimentos e as práticas escolares a uma rede de ensino mais ou menos formal de ensino elementar da leitura, da escrita e do cálculo. A reunião de instituições, idéias 
e práticas dispersas foi o elemento fundamental da organização de espaços fechados, disponíveis à população em geral, e totalmente ordenados para a realização de tarefas, invariavelmente num tempo cuidadosamente regulado para não deixar margens a um movimento imprevisto, em torno de regulamentos para o controle das atividades desenvolvidas nesse estabelecimento. Se nos atermos ao modelo elaborado por Guy Vicent, Bernard Lahire e Daniel Thin (2001, p. 15) acerca da forma escolar, tratou-se do momento de definição de regras constitutivas da ordem escolar oficial no Brasil com vista a estabelecer "não mais uma relação de pessoa a pessoa, mas uma submissão do mestre e dos alunos a regras impessoais".

É difícil dimensionar as mudanças culturais proporcionadas numa estruturação desse tipo. Na historiografia o que parece certo são os elementos fundamentais das mudanças. Dessa perspectiva, um renovado debate sobre os múltiplos discursos, as ênfases e os interesses dos departamentos de instrução pública têm observado no funcionamento da vida escolar e das políticas e reformas educacionais os produtos de práticas não somente historicamente determinadas, mas, sobretudo, socialmente determinantes. Nesse debate, reivindicam-se estudos sobre os modos pelos quais reformas e políticas escolares modificam padrões de trabalho vigentes nas escolas ou são anulados por eles. O repertório de saberes, práticas e materiais empregados no ambiente escolar no momento de sua estruturação institucional impõe relações imprevistas. Nisso reside muito da problemática hoje já bem circunstanciada pela historiografia educacional: na repercussão das políticas públicas sobre a vida escolar há mais que providências técnicoadministrativas.

Aqui, eu gostaria de fazer minha essa problemática, tendo em vista as políticas de educação desenvolvidas na cidade do Rio de Janeiro nas primeiras décadas do século passado. Primeiro, gostaria de examinar como objeto um conjunto de procedimentos e materiais que foram aplicados na instituição escolar sob a forma de signos, de traços, de práticas e de saberes no momento de organização do sistema escolar republicano. Em segundo lugar, determinar a importância das modificações promovidas pelas reformas da instrução pública realizadas na cidade do Rio de Janeiro entre os anos de 1922 e 1935. Em terceiro lugar, pensar as relações de coexistência entre os dispositivos escolares de imposição de modelos culturais elaborados fora da escola e a originalidade das práticas articuladas no interior dessa instituição. E, finalmente, como conclusão, demonstrar que as políticas públicas de ensino incidiram tanto nas estruturas objetivas do sistema escolar quanto nas instâncias culturais de sua disseminação.

Essa opção pela análise das mudanças culturais proporcionadas num momento de reestruturação do aparelho público de ensino não aspira à originalidade; ao contrário, preocupa-se com o dimensionamento dos efeitos das políticas públicas de educação sobre a vida escolar. Dessa perspectiva, o texto está mais vinculado às tarefas metodológicas da investigação histórica acerca das reformas educacionais que ancorado numa concepção de sistema público de ensino pletora de inteligibilidades culturais e sociais. No que me proponho fazer, a pesquisa acerca das possibilidades de análise histórica dos processos de reforma e aquilo que a historiografia educacional tornou referência para a problematização das políticas de reforma educacional na época organizam a apresentação dos resultados.

\section{Reforma educacional e cultura escolar}

A estruturação do ensino elementar organizada durante o período oitocentista aparece com uma tripla função quando vista no interior da administração pública. Constitui, inicialmente, uma operação deliberada do governo, que fixou em projeto político as instituições e procedimentos que lhe convinham. Ela é também o resultado de convicções culturais, pois a configuração de modelos estruturados e organi-zacionais da escola lidou com critérios relacionados com a eficácia, o aproveitamento de recursos, com o melhoramento definitivo dos procedimentos de difusão de saberes. Ela é, enfim, uma criação cultural que a experiência do ensino cotidiano não cessou de modificar, pois gerou conflitos, confrontos e debates relacionados às finalidades atribuídas ao esforço coletivo de organização dos valores, dos saberes e das práticas escolares - arranjo 
que não deixa de ser bastante paradoxal, já que foi, a um só tempo, planejado e imprevisto, já que delimitou o campo de uma cultura da qual ele é o efeito, já que foi o campo de interações e enfrentamentos, e, porque, afinal, não foi simplesmente uma organização oficial presente no discurso dos reformadores, mas aquilo que lhe possibilitou: a rede material e as formalidades das práticas pedagógicas escolares.

Assim entendida, a história da estruturação institucional da escola no Brasil, a história da escola como organização do trabalho educativo, é uma história da própria cultura escolar, como a entende António Viñao Frago (1995, p. 74): “uma história das idéias e dos fatos, de objetos e práticas, de modos de dizer, fazer e pensar". Dessa perspectiva, as posições de poder no campo da educação, os modos de realizar a escolarização e de instituir identidades pessoais e profissionais aparecem como evidências da rede material e das formalidades das práticas pedagógicas que puderam (ou convieram) ser organizadas pelos marcos legais e pela política praticada no interior da esfera governamental. Há nisso uma interseção importante: aquela que relaciona a rede material e as formalidades das práticas pedagógicas escolares disponíveis ao apoio político articulado no interior do legislativo para consolidar deveres profissionais e certas estratégias de ensino e controle dos alunos em regulamentos e leis.

Quando, muito recentemente, a historiografia educacional produziu uma nova abrangência para a escola do período imperial, fez dessa interseção o lugar de organização da rede institucional de escolarização no Brasil. Mas é preciso evitar os equívocos: o que se identifica aí não é o ponto de origem de uma escolarização oficial, é o aparecimento de um modo de ser das escolas. Aquilo que Larry Cuban e David Tyack (1999, p. 86) denominam de gramática escolar serve aqui para expor algo da estrutura produzida para amoldar a maneira pela qual os professores realizavam o seu trabalho na escola primária oitocentista brasileira:

A gramática escolar é um produto da história e não uma criação existente desde os primórdios dos tempos. Ela resulta dos esforços de grupos que se mobilizam para que tanto os problemas definidos por eles quando suas soluções propostas correspondentes sejam respaldadas. Quanto mais poder e prestígio têm os grupos, tanto mais é provável que eles sejam capazes de sustentar suas reformas com leis, regulamentos e exigências de autorizações burocráticas.

Sob disputas desse tipo, o processo de escolarização produzido durante a mobilização empreendida entre as décadas de 20 e 70 do século 19 avançou lenta e restritivamente, mas de modo inexorável. Embora sujeito a sucessivos reparos, consolidou uma continuidade considerável no modo pelo qual os professores ensinavam (Souza, 2000; Hilsdorf, 1999b; Villela, 1992), nos padrões institucionais cotidianos, como controlar o comportamento do estudante, ensinar a alunos com perfis heterogêneos ou organizar deveres complexos (Cardoso, 1999), na organização dos programas escolares (Souza, Valdemarin, Almeida, 1998), e no uso dos espaços e dos tempos educacionais (Vidal, Faria Filho, 2000). Esses modos, padrões e usos vieram a constituir o modo de ser das escolas brasileiras durante o Império.

Por outro lado, as iniciativas dos republicanos não escaparam ao circuito de disputas indicado por David Tyack e Larry Cuban. Elas desafiaram as estruturas e regras constitutivas do modelo de escolarização herdado do Império. Seus domínios de realização, tão incertos em suas fronteiras com o período monárquico, tão indeterminados em seu conteúdo, trazem uma série de problemas.

Logo de início é preciso separar-se de toda uma série de noções ligadas ao postulado do novo. Ficou demonstrado com os trabalhos de Marta Maria Chagas de Carvalho e de Maria Lúcia Hilsdorf como a organização das práticas escolares do período republicano aprofundou as experiências iniciadas pelo ensino intuitivo no fim do século 19. Apresentam um recorte definido pelo trabalho educativo realizado pelas associações de educadores (Carvalho, 1998) ou elaborado no interior das instituições escolares (Hilsdorf, 1977, 1986, 1994). Por conta disso, replicam à periodização estabelecida em referência a história política: sim, mas as relações propriamente escolares... As relações escolares que não são meros domínios de transposição cultural, não são exatamente uma extensão das condições de produção e recepção estatais, são examinadas atualmente no interior da ordem material na qual 
apareceram. O interesse pela materialidade dos dispositivos que realizam o processo educativo e das práticas dos agentes que produzem ou se apropriam desse processo marca não só uma mudança de perspectiva historiográfica, mas o próprio entendimento de como a escolarização se realiza em suas múltiplas facetas em tempos e espaços determinados (Faria Filho, 2002, p. 22).

Uma síntese produzida por Diana Gonçalves Vidal indica as características da dinâmica das relações escolares consolidadas durante os anos 20 do século 20 . Avalia que, nos textos oficiais e na legislação das reformas da instrução carioca, o papel central da criança nos processos educativos, a observância às prescrições da higiene, a cientificidade da escolarização de saberes e fazeres sociais, o ato de observar e o ensino intuitivo voltam a ser enunciados como novas questões para a construção do conhecimento na criança (Vidal, 2000, p. 497). O reconhecimento do fato de que já no fim do século 19 muitas das mudanças afirmadas como novidades pelo "escolanovismo" povoavam o imaginário da escola e eram igualmente reproduzidas, como prescrição, tanto em textos legais quanto em relatórios, torna insustentável muitas das rupturas construídas em torno das novidades introduzidas pelas reformas educacionais na década de 20 do século 20.

Uma vez descartada essa forma prévia de ruptura, todo um domínio acha-se liberado. Ele é constituído pelo encadeamento de um sistema institucional executivo amplo e articulado o suficiente para transformar os limites do processo educacional, o ponto de inflexão de uma prática e o regulamento ou o funcionamento escolar, domínio, portanto, das ações efetivas, na verdade, seu modo de gerir as ações, seu lugar de geração das operações de planejamento, articulação e estruturação do sistema de ensino. Assim, a grande mutação que caracterizou esse encadeamento não foi a expansão do domínio escolar até os mecanismos sociais ou culturais, tampouco foi a integração de fenômenos ideológicos, de formas de pensamento, dos tipos de cultura: o século 19 já os havia realizado durante o Império. É antes a transformação das ações: ao invés dos contratos de compatibilidade e compromissos utilizados para a formação dos socialmente iguais (Carvalho, 1980), a gestão das relações com uma exterioridade distinta, um manejo útil e uma utilização benéfica da escolarização da população pobre (Carvalho, 1989).

Antes de se relacionar com uma ciência, com discursos políticos ou com a iniciativa de um técnico, o material que se tem a tratar é uma população de acontecimentos numa circunstância de reforma. Nela surgem muitas das mudanças afirmadas como novidades nos 20 do século 20. De fato, as apropriações da forma escolar que se desejou modificar durante as reformas desse período ressignificou seus materiais e métodos mais que as unidades previamente dadas de seus enunciados. Nesse sentido, foi preciso não mais sustentar que os esforços de renovação dos procedimentos de escolarização no País colocaram em jogo uma nova cultura escolar ou foram uma manifestação episódica de inovação educacional. Atualmente, são tratados em sua irrupção histórica. O que se tenta observar é a condição de uma emergência: a estruturação de um sistema escolar único, leigo e gratuito.

\section{O campo dos acontecimentos}

Acontecimento significativo, portanto. De início, porque ligado, por um lado, a um gesto de controle ou à articulação institucional dos processos educativos, mas que, por outro lado, abre para si mesmo uma existência permanente no campo de uma memória acerca da escola verdadeira (Cuban, Tyack, 1999) e na materialidade das práticas, dos impressos, dos livros ou de não importa que forma de procedimento educacional (Carvalho, 2000; Vidal, 2000). A seguir, porque modifica, mesmo que lentamente, os processos de comunicação e as formas de constituição dos sujeitos nas suas dimensões simbólica e material. Finalmente, porque determina áreas de inclusão e exclusão dos esforços de escolarização da sociedade:

Surge assim, inevitavelmente, o que poderíamos chamar uma cultura escolar pública ou certificada, no sentido de que dá direito a obtenção de certos títulos, e de uma cultura escolar privada, não necessariamente certificada porém que contribui com a formação geral do indivíduo. Nela incluiríamos todos os movimentos 
surgidos na periferia do sistema escolar globalmente considerados como educação popular - que vislumbraram e o seguem fazendo diversos momentos da história educativa (Pintado, 2000, p. 226).

Mais que pela polarização entre o "novo e o velho", o moderno e o tradicional, indicada nas intervenções promovidas durante a transição do Império para a República, é pela produção dessa cultura escolar pública da qual fala Pintado que se pode determinar algo da importância das modificações promovidas pelas reformas da instrução pública realizadas na cidade do Rio de Janeiro entre os anos de 1922 e 1935. No horizonte desse período, talvez seja esse o tema geral: o do modo de existência do aparelho escolar no sistema de sua institucionalização. Para fixá-la trabalharam Carneiro Leão (1922-1926), Fernando de Azevedo (1927-1930) e Anísio Teixeira (1931-1935).

$\mathrm{O}$ que se tratou de fazer aparecer foi o conjunto de condições para unificar o ensino primário num só sistema de escolarização. Desde muito cedo, a discussão acerca da gratuidade do ensino oferecido pela municipalidade do Distrito Federal foi crucial na organização da escola como um serviço público. O seu significado para as administrações Carneiro Leão, Fernando de Azevedo e Anísio Teixeira traduziu-se na organização de uma rede de instituições comprometida com o envolvimento do maior número de indivíduos possível no quadro de referências sociais do conhecimento. Nas diferentes configurações que tiveram essas administrações, foi comum o esforço de expandir a educação primária. Inicialmente pela gratuidade e, progressivamente, pela obrigatoriedade escolar, as políticas públicas de instrução no Distrito Federal fizeram entender que, longe de ser privilégio, a educação era uma necessidade. Com esse sentido pretenderam abrir o sistema de educação ao grande público.

Nessa época, tal abertura vinha baseada em uma definição perfeitamente clara do tipo de escola capaz de oferecer uma educação comum a sua população. A escola única que Fernando de Azevedo apresentou nos programas escolares fazia da gratuidade, da escola graduada, do ensino laico, dos métodos ativos, do espaço apropriado para o trabalho educativo e da presença de um professor profissionalizado um modelo institucional para o ensino primário. Em nome desse mesmo modelo também Antônio Carneiro Leão e Anísio Teixeira produziram estruturas de organização e estratégias de negociação vinculadas à montagem de um repertório escolar adequado a um novo público presumido: a criança do povo, aquela que só tinha a escola, nem livros, nem revistas, nem o exemplo da leitura, nem, o que parecia pior, a necessidade da leitura (Teixeira, 1953, p. 63).

O resultado pareceu ser a Anísio Teixeira (1953, p. 26 e 28) o progressivo abandono do caráter acadêmico da escola primária e a sua identificação com a vida e as suas necessidades, a marcha para uma relativa eficiência. Se essa interpretação parece válida é por causa do investimento feito na modificação de pelo menos quatro componentes das práticas escolares.

A regulamentação. Inicialmente, as regulamentações parecem ser o lugar em que os enunciados sobre a educação formam um conjunto, na medida em que elas se referem à redefinição das estratégias de controle dos processos educativos. Nas diferentes reformas da instrução do período, os enunciados referentes à educação, ou à escola, por exemplo, não têm todos certamente o mesmo nível formal ou então semântico conforme sejam programas escolares, códigos legislativos, artigos de pedagogia ou outros documentos. Mas todos se relacionam com esse objeto que se perfila de diferentes maneiras na experiência individual ou social, e que se designava como educação. Esses enunciados relativos à educação, e que eventualmente a constituem, foram modificados por Carneiro Leão, Fernando de Azevedo e Anísio Teixeira: não são absolutamente as mesmas funções administrativas, as mesmas correlações técnicas ou, ainda, as mesmas práticas que visavam; entretanto, sancionaram um referencial de educação pública colocado em ação por um conjunto de enunciados cuja unidade se encontra precisamente definida pelas transformações desse referencial. Paradoxalmente, descrever o alcance dessas transformações no que ele traz de novo não consiste em determinar as rupturas produzidas pelas reformas da instrução, em fixar as modificações que impuseram, em descrever os procedimentos que ela inaugura. Ao contrário, é descrever as estratégias de circulação de seus enunciados, apreender o modo como foram obtidos os resultados 
mais eficazes e de maior importância, indiciar os recursos mobilizados para realizar os processos de escolarização - em outros termos, perceber as apropriações do modelo escolar vigente, as ressignificações de materiais e métodos escolares já disseminados socialmente.

A docência. Outro componente de articulação das práticas e saberes escolares, a profissão docente caracteriza uma instância cultural específica no interior das instituições escolares. Por ela passaram os processos de construção do discurso científico em educação, as políticas de profissionalização do ofício e a articulação das práticas de renovação do trabalho e dos saberes educativos nas diferentes tentativas de reforma da instrução durante a República. Com as administrações Carneiro Leão, Fernando de Azevedo e Anísio Teixeira não foi diferente. Ocorre, entretanto, que eles impõem uma nova possibilidade de formação ao professorado público; eles fundaram novamente a possibilidade de atualização profissional por meio de cursos. Cursos de férias, cursos em conferências ou cursos universitários confrontaram o magistério carioca não só com técnicas de trabalho, de interpretação e de atualização, mas, principalmente, com a possibilidade de uma formação complementar à Escola Normal ou mesmo em sua substituição. E o efeito político, a espécie de agitação provocada no interior dos quadros burocráticos da administração da instrução pública, veio provavelmente do fato de essas iniciativas reconstituírem aquilo que o próprio Carneiro Leão (1942, p. 78) reconhecia ser apenas a "generalização de uma orientação definida”.

Serviu também, entretanto, para distinguir as funções implicadas num momento de reforma do ensino. A mais nítida é aquela que diferencia entre os pares as autoridades responsáveis pela enunciação da orientação geral, ou mesmo pela sua definição, daqueles simplesmente autorizados a praticar ou reexperimentar as novas diretrizes do trabalho educativo. Foi nesse campo que incidiram as diferentes estratégias de nomeação, promoção e formação desenvolvidas por Carneiro Leão e Fernando de Azevedo num primeiro período de reforma e, depois, a reorganização administrativa no departamento de educação iniciada com Fernando de Azevedo e inteiramente efetivada por Anísio Teixeira. No intervalo de 13 anos, que separa a reforma Carneiro Leão da reforma Anísio Teixeira, ficou consolidada uma nova rede de circulação dos saberes pedagógicos, das relações de força e das exigências da profissionalização. Mais que a distinção identificada por Agustin Escolano (1999, p. 23) entre uma cultura normalista, responsável pela aplicação das práticas educativas, e outra, teórica, chamada de cultura pedagógica, é a disseminação de possibilidades para a construção de uma carreira no interior do ofício de docente que parece importante destacar no período. Para além de uma diferenciação entre uma cultura dos reformadores, técnicos, administradores, inspetores e uma cultura dos professores primários (Frago, 2003, p. 8), é preciso reconhecer a elaboração de canais de acesso entre uma instância e outra num momento de consolidação dos quadros do magistério público. A formação de comissões de trabalho coletivo, a organização dos cursos de conferências, os procedimentos de promoção e nomeação nas administrações Carneiro Leão e Fernando de Azevedo (em que a disponibilidade foi inclusive adotada como forma de renovação dos quadros docentes) e a organização do Instituto de Educação com seus respectivos cursos de nível superior na administração Anísio Teixeira procuraram absorver as possíveis diferenças numa mesma orientação geral: reformar a prática.

$O$ espaço escolar. O terceiro componente influente das práticas escolares é o espaço onde elas se desenvolvem. Mais que a estrutura na qual deságua a ação escolar, os edifícios escolares enunciam um programa de formação, sustentam uma política de controle dos movimentos e dos costumes. Os grupos escolares concebidos e construídos durante o século 19 como verdadeiros templos do saber (Souza, 1998) tiveram uma nova planificação nas administrações Fernando de Azevedo e Anísio Teixeira. Monumentais e suntuosos ou econômicos e funcionais, os edifícios construídos entre 1928 e 1935 alimentaram os ideais de uma reconstrução da própria vida pela escola (Carneiro Leão, 1942, p. 74-75; Azevedo, 1930, p. 22; Teixeira, 1953, p. 222). Incorporaram ambientes freqüentados e de experimentação. Consolidaram princípios educativos e reorganizaram a distribuição do espaço da sala de aula. Ligaram a aprendizagem a uma 
simbologia estética, cultural e ideológica veiculadas pela República ou constituída pelos modernismos de diferentes matizes. Em todos os casos, fizeram conviver com uma educação racional e científica visando à observação e à sistematização do comportamento infantil, à experimentação de novos métodos e práticas pedagógicos vinculados à realidade brasileira, bem como à visibilidade das mudanças implementadas pela ação reformadora no Brasil (Vidal, Faria Filho, 2000, p. 2930). Seria esse conjunto de enunciados, princípios e conseqüências a perpetuação de uma mudança dos repertórios de funcionamento escolar: a distribuição dos espaços.

O tempo escolar. Finalmente, um último componente influente das práticas escolares é o tempo no qual elas ocorrem. No ponto de partida, o problema é definir o que seria legítimo considerar como modalidade do tempo escolar. A seqüência, curso ou sucessão continuada dos momentos em que se distribuem os processos e ações educativas é a definição geral que Escolano apresenta (1992, p. 56). O registro que Viñao Frago faz do tema acrescenta que se trata de um tempo diverso e plural, individual e institucional, condicionante e condicionado por outros tempos sociais - em suma, "um tempo aprendido que conforma a aprendizagem do tempo; uma construção cultural e pedagógica; um eixo cultural” (Frago, 1995, p.72). É nesse sentido que a distribuição diária, semanal, mensal e anual do processo de ensino indica a duração do período de aula, a grade de horário das disciplinas, das atividades e do repouso, os parâmetros de controle e planejamento do trabalho docente. Mas não só: a composição dos programas escolares, o período de escolarização do indivíduo ou mesmo a instituição da escola seriada não só determinaram, mas obedeceram supostos psicológicos e pedagógicos, valores e princípios sociais, bem como um tempo a interiorizar e aprender.

Desse modo, a determinação da duração do ensino primário em cinco anos, a institucionalização das escolas de dois turnos, a flexibilização dos tempos de duração das lições e a modificação dos tempos de duração das atividades empreendidas no percurso pelo qual as sucessivas reformas da instrução pública do período construíram a idéia de escola-laboratório completaram a transformação dos critérios de eficácia e de aproveitamento dos recursos da escolarização. Enquanto alvo dessas reformas, o tempo escolar foi reorganizado em meio às diversas resistências, mas encontrou nos edifícios escolares um espaço definido para funcionar. É preciso, portanto, considerar que, nessa situação, a organização temporal de escolas com espaço próprio para realizarem-na elevaram o grau de institucionalização da instrução pública. Tornou mais efetiva, simbólica e materialmente, a escola pública junto à população ao preço de um distanciamento das sensibilidades, dos valores, dos ritmos e ritos do espaço doméstico que Faria Filho (2002, p. 29) identificava nas escolas isoladas nas primeiras décadas do século passado.

Tanto os aspectos da escolarização formalizados pelos regulamentos do ensino publicados durante os movimentos de reforma da instrução entre 1922 e 1935 quanto seus efeitos na profissionalização e orientação do trabalho docente terminaram por desenhar um conceito determinante de renovação. Incluída nessa mesma afirmação tem-se como resultado imediato uma modificação da organização espacial e temporal da instituição escolar influente no trabalho de administração e inspeção das práticas educacionais. De fato, é possível, a partir desses componentes da elaboração da cultura escolar pública, definir um entendimento das reformas da instrução que dê conta não somente de suas realizações, mas de suas estratégias de implementação e, eventualmente, da configuração de suas disputas. Esse entendimento não é constituído por outros enunciados ou por outros saberes do que aqueles que aparecem na superfície material das instituições escolares ou daqueles manipulados às claras no cotidiano escolar. Ele é, assim, constituído por um conjunto de vestígios ordinários da cultura escolar. Esse conjunto vai desde os aspectos formais da materialidade dos objetos escolares ou de escolarização até os procedimentos de realização política das reformas da instrução pública.

\section{As formações culturais e a escolarização}

Há, nesse itinerário, relações descritíveis entre os dispositivos escolares de imposição de modelos culturais elaborados fora da escola e a originalidade das práticas articuladas no seu interior. Elas se supõem entre si, derivam uma da 
outra e, encadeando-se, ligam discursos que não podem ser sobrepostos. Elas constituem o que se poderia chamar de formações culturais: a circulação das representações produzidas pelo encontro entre os saberes e os materiais culturais disponíveis num momento dado numa sociedade e a oferta social de elementos diversos de origem puramente escolar ou de leis e funcionamento do sistema escolar. Não convém, portanto, entender esse termo como uma espécie de estruturante mental ou social facilitadora da distribuição do capital cultural, e, por isso, da reprodução da estrutura do espaço social conforme o modelo de análise utilizado por Pierre Bourdieu (1991, p. 117). Foi antes como o conjunto de heterogeneidades, incompatibilidades e pluralidade constitutivas das diferentes identidades sociais formadoras de uma determinada comunidade política que as formações culturais estiveram na alça de mira das reformas da instrução pública.

Se é lícito reconhecer nas funções e instituições escolares a possibilidade de inovação é porque todos os materiais e os saberes que por meio delas se configuram, se encadeiam, se entrecruzam, interferem uns nos outros, se mascaram e são conformados a partir de múltiplas facetas, diferentes agentes, em tempos e espaços determinados. Tudo isso esteve coberto nas políticas de educação organizadas nas administrações Carneiro Leão, Fernando de Azevedo e Anísio Teixeira por um conjunto de medidas sistemáticas: a escolarização de novos conhecimentos, a incorporação de novos espaços educativos, as políticas de edificação escolares e a consolidação de toda uma rede de assistência e proteção da infância. Foram medidas admitidas para instaurar, no campo de acontecimentos das reformas da instrução, outros modos de enunciação do cultural no interior da instituição escolar, mais dependentes, como observa Jean-Claude Fourquin (1992, p. 42), da codificação escrita e que dão lugar mais facilmente a procedimentos de avaliação formal.

Inversamente, existiram resultados mais silenciosos ou, ao menos, pouco aludidos no momento de realização dessas reformas educacionais. As modificações dos programas escolares realizadas no interior da instrução primária não generalizaram exatamente um certo status quo, previsto e organizado nos programas de ensino a partir de um repertório de estratégias multiplicado pela utilização dos métodos ativos, mas originou outros repertórios. Toda a série de reflexões políticas, de programas de reforma, de medidas legislativas, de regulamentos administrativos e de considerações morais obtidas pelo fazer administrativo definiram os pontos de escolha que tornaram possíveis, em sua própria organização, a repetência e a evasão escolares. A intensificação do trabalho escolar especializou as funções e as práticas docentes, notavelmente naquilo que lhes conferia profissionalização dentro da estrutura educacional, dando ao sistema a característica de um mercado de trabalho e de consumo das produções cada vez mais elaboradas das casas editoriais. O conjunto espaço-temporal formado pelos edifícios escolares constituiu uma modalidade enunciativa simultaneamente teórica e prática, descritiva e institucional, analítica e prescritiva, composta tanto de afirmações como de regulamentos, incapaz de interromper as múltiplas forças insidiosas e móveis, seja dos recursos políticos, seja das formas delinqüentes. Assim, esteve sujeito às disputas incessantes pela circunscrição de uma vivência original.

Não é menos verdade que seja possível descrever um certo número de soluções didáticas que favoreceram a formalização de conhecimentos ou práticas antes não escolarizadas. O detalhamento dos programas de higiene e de educação social ou moral e cívica, das prescrições para o ensino da história e da geografia ou das indicações para as atividades físicas na escola compunham seções previstas em todos os programas de instrução primária publicados entre 1922 e 1935. Por outra parte, as solicitações metodológicas provenientes da orientação pedagógica adotada nesses programas fizeram dos aparelhos conceituais que os mecanismos didáticos efetivavam parte de uma narração cotidiana: a escola devia formar o espírito infantil simultaneamente com a utilização dos métodos de ensino-aprendizagem ou experimentação, dos exercícios de aplicação ou de análise e das atividades de experimentação. Ensinar na escola sob essas condições era necessariamente efetivar alguma educação. Seria preciso não ver nesses repertórios um efeito das soluções didáticas para reconhecer aí somente um trabalho de reorganização, de reestruturação dos 
materiais culturais socialmente disponíveis no momento, conforme fica indicado no conceito de transposição didática elaborado por Fourquin (1992, p. 32). De fato, parece haver aí um trabalho com consistência própria, com leis de funcionamento e disposição autônoma. Nesse sentido, muito do que escapou aos processos de reforma do ensino foi aquilo mesmo que, nas considerações de André Chervel (2002, p. 192), fez da disciplina escolar um fenômeno cultural, isto é, os fatos próprios e restritos à escola e que não puderam em momento algum ser exatamente referidos às ciências, às artes ou a quaisquer outras práticas culturais.

\section{Formacões culturais, estruturas objetivas e efeitos imprevistos}

A análise das reformas da instrução articuladas pelas políticas públicas de educação na cidade do Rio de Janeiro entre os anos de 1922 e 1935 concerne à definição das formações culturais que conseguiram alcançar ou, inversamente, lhes atingiram. É, em parte, uma descrição do sistema de relações de forças entre os grupos que buscavam controlar as transmissões ou apropriações educacionais. Concerne, igualmente, à identificação dos conhecimentos, dos temas e do repertório de fatos que firmaram os modelos de escolaridade implementados por essas políticas de educação. Constitui ainda uma reflexão acerca dos acontecimentos, dos episódios, dos obstáculos, das dissidências, das expectativas, dos atrasos e das facilitações que marcaram o campo da história efetiva das reformas da instrução pública desse período. Fazer emergir esses níveis de funcionamento e eficácia, definir esses pontos de aplicação e identificar as representações que essas reformas puderam dar lugar repercute duas formas de germinação silenciosas que têm, cada uma, um papel mobilizador simétrico e oposto: a germinação de estruturas objetivas e a germinação de efeitos imprevistos.

A germinação de estruturas objetivas deu-se na medida em que as reformas educacionais conseguiram consolidar instituições geradoras e unificadoras das escolhas em matéria de modelos de escolaridade. Ela permite não só a verificação do alcance institucional das modificações implementadas, mas a identificação dos dispositivos utilizados para a apropriação dos sistemas de preferências implicados no reposicionamento dos discursos, das técnicas e dos sujeitos numa circunstância de reforma educacional. Eis porque, com a descrição das condições externas de aparecimento dos enunciados de reforma, impõe-se a tarefa de decifrar a organização interna dos departamentos de instrução e as suas normas formais de funcionamento. Muitos traços dessa decifração apontam para a administração central do sistema escolar consolidado no Distrito Federal como o lugar de formação das opções teóricas daquilo que viria a ser o movimento escolanovista, o centro articulador das modificações que as políticas de educação na cidade do Rio de Janeiro experimentaram entre os anos de 1922 e 1935.

A germinação dos efeitos imprevistos incidiu sobre o modelo de escolarização estruturado e implantado pelas reformas articuladas por Carneiro Leão, Fernando de Azevedo e Anísio Teixeira limitando as circunstâncias de sua efetivação. Ela lhe foi exterior e muito pouco passível de sobreposição, pois se trataram de disposições autônomas: lances de resistência, ocasiões de subversão, repertórios de astúcias. Foi, portanto, constituída por um conjunto de enunciados que não tinham o mesmo estatuto, o mesmo recorte, a mesma organização, nem o mesmo funcionamento das estruturas objetivas pelas quais se disseminava. Diversas ocorrências ordinárias permitiriam caracterizar melhor os efeitos imprevistos articulados com a generalização e expansão do modelo de escolaridade regulamentado nessas reformas. De fato, a indisciplina, a repetência e a evasão escolares, a tecnocracia implantada com a profissionalização docente e as disputas políticas pelo controle do aparelho educacional verificadas nas malhas do sistema público de ensino que se procurou instalar indicaram o real alcance dessas influências mudas na ação dos reformadores. Fernando de Azevedo (1946, p. 132) percebeu-as bem:

a consciência da estreiteza relativa de nosso círculo de ação, limitando a concepção larga de mais de nosso papel, no conjunto das influências educativas que se exercem fora de toda a intervenção consciente de nossa parte. 
Em atenção a toda essa germinação difusa, pode-se dizer que as formações culturais com que lidaram as políticas públicas de ensino permaneceram disseminadas pela sociedade, apesar de todas as tentativas para articulá-las à esfera estatal. De todas as manobras pelas quais se quis determinar um modelo de escolarização popular, parece provável que esta tenha sido, durante quase meio século, aquela que animou o tema de uma política pública de educação, perpetuamente ligada aos aparelhos de Estado e infinitamente aberta às tarefas de estruturação administrativa dos processos de transmissão cultural. Pareceu necessário um aparato institucional articulado ao Estado para que a escolarização constituísse um fenômeno cultural; mas pareceu reciprocamente preciso que reivindicações difusas atravessassem as instituições escolares para que estas consolidassem sua dimensão pública. Assim, entre 1922 e 1935, as políticas públicas de educação desenvolvidas na capital federal foram assumidas como obras de reconstrução institucional do aparelho escolar e desenvolvidas como políticas de governo.

\section{Referências bibliográficas}

AZEVEDO, Fernando de. A educação e seus problemas. 2. ed. São Paulo: Ed. Nacional, 1946.

A escola nova e a reforma: introducção aos programmas de escolas primarias. Boletim de Educação Publica, Rio de Janeiro, v. 1, n. 1, p. 7-23, jan./mar. 1930.

BASTOS, Maria Helena Camara; FARIA FILHO, Luciano Mendes de (Org.). A escola elementar no século XIX: o método monitorial/mútuo. Passo Fundo: Ediup, 1999.

BOURDIEU, Pierre. Estruturas sociais e estruturas mentais. Teoria \& Educação, Porto Alegre, n. 3, p. 113-119, 1991.

CARDOSO, Teresa Maria Fachada. Abrindo um novo caminho: o ensino mútuo na escola pública do Rio de Janeiro (1823-1840). In: BASTOS, Maria Helena Camara; FARIA FILHO, Luciano Mendes de (Org.). A escola elementar no século XIX: o método monitorial/mútuo. Passo Fundo: Ediup, 1999. p. 119-143.

CARVALHO, José Murilo de. A construção da ordem: a elite política imperial. Rio de Janeiro: Campus, 1980.

CARVALHO, Marta Maria Chagas de. A escola e a República. São Paulo: Brasiliense, 1989.

. Molde nacional e fôrma cívica: higiene, moral e trabalho no projeto da Associação Brasileira de Educação (1924-1931). Bragança Paulista: Edusf, 1998.

. O novo, o velho, o perigoso: relendo a Cultura Brasileira. Cadernos de Pesquisa, São Paulo, n. 71, p. 29-35, nov. 1989.

. Reformas da Instrução Pública. In: LOPES, Eliane Marta Teixeira; FARIA FILHO, Luciano Mendes; VEIGA, Cynthia Greive. 500 anos de educação no Brasil. 2. ed. Belo Horizonte: Autêntica, 2000. p. 225-496.

CHERVEL, André. La culture scolaire: une approche historique. Paris: Belin, 2002. 
CUBAN, Larry; TYACK, David. Tinkering toward utopia. A century of public school reform. Boston: Harvard University Press, 1999.

ESCOLANO, Agustín. Los professores en la historia. In: MAGALHÃES, Justino; ESCOLANO, Agustín (Org.). Os professores na história. Porto: Sociedade Portuguesa de Ciências da Educação, 1999. p. 15-27.

Tiempo y educación. Notas para una genealogía del almanaque escolar. Revista de Educación, n. 298, p. 52-69, 1992.

FARIA FILHO, Luciano Mendes de. Escolarização, culturas e práticas escolares no Brasil: elementos teórico-metodológicos de um programa de pesquisa. In: LOPES, Alice Casimiro; MACEDO, Elizabeth. Disciplinas e integração curricular: história e políticas. Rio de Janeiro: DP\&A, 2002. p. 13-35.

Estado, cultura e escolarização em Minas Gerais no século XIX. In: VIDAL, Diana Gonçalves; SOUZA, Maria Cecília Cortez Christino de (Org.). A memória e a sombra - a escola brasileira entre o Império e a República. Belo Horizonte: Autêntica, 1999. p. 117-126.

FOURQUIN, Jean-Claude. Saberes escolares, imperativos didáticos e dinâmicas sociais. Teoria \& Educação, Porto Alegre, n. 5, p. 28-49, 1992.

FRAGO, António Viñao. Historia de la educación e historia cultural: posibilidades, problemas, cuestiones. Revista Brasileira de Educação, São Paulo, n. 0, p. 63-82, set./dez. 1995.

. Culturas escolares. [S.1.], 2003. 8 p. Mimeografado.

HILSDORF, Maria Lúcia Spedo. A série Ofícios Diversos do Arquivo do Estado de São Paulo como fonte para a história da educação brasileira. In: VIDAL, Diana Gonçalves; SOUZA, Maria Cecília Cortez Christino de (Org.). A memória e a sombra - a escola brasileira entre o Império e a República. Belo Horizonte: Autêntica, 1999a. p. 13-20.

. Escolas americanas de confissão protestante na Província de São Paulo: um estudo de suas origens. 1977. Dissertação (Mestrado) - Faculdade de Educação, Universidade de São Paulo, São Paulo, 1977.

Francisco Rangel Pestana: jornalista, político, educador. 1986. Tese (Doutorado) Faculdade de Educação, Universidade de São Paulo, São Paulo, 1986.

Métodos de educação popular na propaganda republicana 1870-1889. Cadernos de História e Filosofia da Educação, São Paulo, v. 2, n. 3, p. 67-78, 1994.

. O ensino mútuo na Província de São Paulo: primeiros apontamentos. In: BASTOS, Maria Helena Camara; FARIA FILHO, Luciano Mendes de (Org.).A escola elementar no século XIX: o método monitorial/mútuo. Passo Fundo: Ediup, 1999b. p. 197-216.

LEÃO, Antônio Carneiro. Planeja e agir. Rio de Janeiro: Jornal do Commercio - Rodrigues \& C., 1942.

LOPES, Eliane Marta Teixeira; FARIA FILHO, Luciano Mendes; VEIGA, Cynthia Greive. 500 anos de educação no Brasil. 2. ed. Belo Horizonte: Autêntica, 2000.

NUNES, Clarice. História da educação brasileira: novas abordagens de velhos objetos. Teoria \& Educação, Porto Alegre, n. 6, p. 151-181, 1992. 
PINTADO, Antonio Molero. En torno a la cultura escolar como objeto histórico. In: BERRIO, Julio Ruiz (Ed.). La cultura escolar de Europa: tendências históricas emergentes. Madri: Biblioteca Nueva, 2000. p. 223-228.

SOUZA, Maria Cecília Cortez Christiano de. A escola e a memória. Bragança Paulista, SP: Edusf, 2000.

SOUZA, Rosa Fátima de. Templos de civilização. São Paulo: Unesp, 1998.

SOUZA, Rosa Fátima de; VALDEMARIN, Vera Teresa; ALMEIDA, Jane Soares de. O legado educacional do século XIX. Araraquara: Unesp, 1998.

TEIXEIRA, Anísio. Educação para a democracia: introdução a administração educacional. 2. ed. São Paulo: Ed. Nacional, 1953.

VEIGA, Cynthia Greive. Educação estética do povo. In: LOPES, Eliane Marta Teixeira; FARIA FILHO, Luciano Mendes; VEIGA, Cynthia Greive. 500 anos de educação no Brasil. 2. ed. Belo Horizonte: Autêntica, 2000. p. 399-422.

VICENT, Guy; LAHIRE, Bernard; THIN, Daniel. Sobre a história e a teoria da forma escolar. Educação em Revista, Belo Horizonte, n. 33, p. 7-47, jun. 2001.

VIDAL, Diana Gonçalves. Escola Nova e processo educativo. In: LOPES, Eliane Marta Teixeira; FARIA FILHO, Luciano Mendes; VEIGA, Cynthia Greive. 500 anos de educação no Brasil. 2. ed. Belo Horizonte: Autêntica, 2000. p. 497-517.

VIDAL, Diana Gonçalves; FARIA FILHO, Luciano Mendes de. Os tempos e os espaços escolares no processo de institucionalização da escola primária no Brasil. Revista Brasileira de Educação, Campinas, n. 14, p. 19-34, maio/jul. 2000.

VIDAL, Diana Gonçalves; FARIA FILHO, Luciano Mendes de; SOUZA, Maria Cecília Cortez Christino de (Org.). A memória e a sombra - a escola brasileira entre o Império e a República. Belo Horizonte: Autêntica, 1999.

VILLELA, Heloísa. A primeira escola normal do Brasil. In: NUNES, Clarice (Org.). O passado sempre presente. São Paulo: Cortez, 1992. p. 17-42.

André Luiz Paulilo, mestre em Educação pela Universidade de São Paulo (USP), é doutorando em Educação na área de História da Educação e Historiografia nessa universidade, professor titular de História na rede municipal de ensino de São Paulo e integrante do grupo de pesquisa em História da Educação (Grupohist) sediado no Centro de Memória da USP.

paulilo@usp.br

\section{Abstract}

The article refers to the overtaking of the public instruction reforms in the transformation of the Brazilian scholar culture between 1922 and 1935. It points out the importance of the public politics of the education in Rio de Janeiro city to organise a national school system. It discourses about the accounts of the experience of the reform showing the valorisation of the strategy statute and pedagogic practice in the arrangement 
of public politics. It concludes indicating how the institutional reconstruction of the school developed itself as a governing politic.

Keywords: history of education; educational reform; school culture; public instruction; cultural history.

Recebido em 15 de agosto de 2003.

Aprovado em 22 de janeiro de 2004. 